\title{
Metal Workers with Corneal Injuries and Abuse of Topical Drugs
}

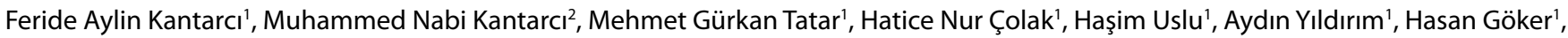
Bülent Gürler ${ }^{1}$

'Department of Ophthalmology, Fatih University, İstanbul, Turkey

${ }^{2}$ Department of Forensic Medicine, Ministry of Justice, Forensic Science Institue, İstanbul, Turkey

\begin{abstract}
Aim: We evaluated metal workers injured with corneal foreign bodies (FB) in terms of health insurance, use of protective eyeglasses, and unprescribed drug use.

Materials and Methods: Seventy metal workers who were injured with corneal FB were enrolled in the study. We recorded the gender, age, duration of work, use of protective eyeglasses, and health insurance status data of metal workers. In cases of FB existence, the number of FBs and unprescribed drug use were investigated. We examined the presence of corneal scars that could lead to visual impairment.

Results: The mean duration of work was $11.8 \pm 10.8$ years. Although 29 workers (41.5\%) had corneal scars, only three workers (4.3\%) had visual impairment due to scars. Also, 29 workers (41.5\%) did not report the use of protective glasses; however, 22 (31.4\%) workers reported their occasional use and 19 (27.1\%) workers reported their routine use. Eighteen workers (25.7\%) remarked on topical drug use from time to time. Ten of the 18 patients $(55.6 \%)$ were using topical Tetrahydrozoline $\mathrm{HCL}$, whereas five (27.8\%) were using the topical anesthetic drug $0.5 \%$ Proparacaine $\mathrm{HCl}$.

Conclusion: Occupational protective measures are important for metal workers who are at a high risk of eye injuries. Workers must be educated on the prevention and treatment of occupational ophtalmological hazards and be warned about the side effects of taking unprescribed drugs. (Eurasian $J$ Emerg Med 2016; 15: 15-9)
\end{abstract}

Keywords: Abuse topical drug, corneal foreign body injuries, goggles, work-related eye injury

\section{Introduction}

Work-related eye injuries (WREI) lead to substantial loss of the workforce as well as increased care and treatment costs and a decreased quality of life (1). Social Security statistics indicate that the incidence of work-related injuries in Turkey is between 70,000 and 80,000 (2). More than 1.3 million work-related injuries that caused at least one day of loss of the workforce were reported in the United States, of which 36,680 of the work-related injuries were eye injuries (3). Eye injuries are generally common among work-related injuries (4). WREI are especially frequent among workers in the metal industry (3-6). Eye injuries have been reported to be more common during machining and plating $(4,5)$. WREI occur due to exposure to projections or sharp objects, hazardous light, and chemical liquids or gases (1).

Work-related eye injuries among metal workers range from corneal superficial epithelial defects to perforating injuries that can cause blindness $(6,7)$. The most common and most easily preventible eye injuries are superficial corneal foreign body injuries (CFBI) (5). A study reported the frequency of CFBI among metal workers in Turkey as being $37 \%$ (8). Secondary infection may also develop due to CFBI, ranging from keratitis to endopthalmitis (9). Vision loss may develop because of scar development at the visual axis (5). CFBI is an ophtalmological emergency, and the foreign body must be removed from the cornea with a 25-gauge needle in a non-traumatic fasion. Postoperative proliferative antibiotic treatment has also been administered (9).

In Turkey, workers who are exposed to work-related eye injuries may use unprescribed drugs. Serious side effects, especially due to the unprescribed use of drugs, which may result in keratoplasty, have been reported (10-13). It is known that the appropriate use of safety equipment, such as goggles, decreases the risk of eye injuries (1, 3, $9,14)$. Workers may be exposed to lights and particles during welding and cutting; therefore, workers must protect their exposed body parts, including their eyes and hands (1). It has been reported that the cost of WREI in terms of lost productivity, covered health care, and compensations exceed 300 million dollars in the United States. It has been stressed that eye injuries can be prevented with protective measures and training (3).

In our study, our aim was to evaluate the health insurance status, use of protective eye wear, and unprescribed drug use among metal workers with superficial cornea injury due to foreign bodies.

Correspondence to: Feride Aylin Kantarcı e-mail: drferideaylin@hotmail.com 


\section{Materials and Methods}

Seventy metal workers with a history of eye injury due to a foreign body in their eyes were prospectively evaluated at Fatih University, School of Medicine, ophtalmology outpatient clinic. Participants were informed about the study, and their consent was obtained before the study. This study complies with the tenets of the Declaration of Helsinki and was approved by the local ethics committee of Fatih University. Gender, age, duration of work, use of protective glasses, and the health insurance status of the study metal workers with CFBI were recorded.

The corneal injuries were superficial and none of the eyes required primer suturation surgery. The questionnaires were completed through in-person interviews and through comprehensive ocular

Table 1. Distribution of descriptive characteristics

\begin{tabular}{|l|c|}
\hline Parameters & \\
\hline Age (years) (mean \pm SD) & $33.7 \pm 8.9$ \\
\hline Gender (Male) $\mathrm{n}(\%)$ & $70(100)$ \\
\hline Health Insurance Status (yes) & $68(97.1)$ \\
\hline Duration of work (years) (mean \pm SD) & $11.8 \pm 10.8$ \\
\hline Number of foreign bodies (mean \pm SD) & $10.9 \pm 11.2$ \\
\hline Corneal scar, $\mathrm{n}(\%)$ & $29(41.5)$ \\
\hline Vision loss, $\mathrm{n}(\%)$ & $3(4.3)$ \\
\hline Goggle use, $\mathrm{n}(\%)$ & \\
\hline Occasional & $22(31.4)$ \\
\hline Routine & $19(27.1)$ \\
\hline Drug use (Yes) $\mathrm{n}(\%)$ & $18(25.7)$ \\
\hline Proparacaine & $5(27.8)$ \\
\hline Proparacaine-Diclofenac & $1(5.5)$ \\
\hline Tetrahydrozoline & $10(55.6)$ \\
\hline Diclofenakc sodium & $2(11.1)$ \\
\hline SD: standard deviation; Min-Max: minimum-maximum \\
\hline
\end{tabular}

examinations. Ophtalmological examination included best corrected visual acuity per Snellen chart, anterior segment, and fundus examinations. In the examination of the anterior segment, corneal scars due to a foreign body, and cataracts that might lead to visual impairment were examined with a slit-lamp biomicroscopy.

\section{Statistical analysis}

The Number Cruncher Statistical System (NCSS) 2007 and Power Analysis and Sample Size (PASS) 2008 Statistical Software (Utah, USA) were used for the statistical analysis. Along with the descriptive statistical methods (Mean, Standard Deviation, Median, Frequency, Rate, Minimum, Maximum), the suitability of the data regarding the normal distribution were determined by the Kolmogorov-Smirnov test together with the number of cases. The relevant variables with normal distribution for the two groups were compared with Student's t test, whereas analysis of variance (ANOVA) tests were used in the evaluation of the three groups, and the Bonferroni test was used for post-hoc analysis. When there were three or more groups to compare for variables which did not have a normal distribution, the Kruskal-Wallis test was used. The Mann-Whitney $U$ test was used to determine the group causing differences. Significance was evaluated at the $p<0.05$ level.

\section{Results}

This study involved 70 male metal workers. The mean ages were 33.8 \pm 8.9 (range 16-53) years. The mean duration of work was $11.8 \pm 10.8$ (range: 6 months to 40 years) years. The mean estimated number of CFBI was $10.9 \pm 11.2$, with a range of $1-50$ (Table 1).

In anterior segment examination, 29 workers (41.5\%) were found to have corneal scars. Three workers with corneal scars had decreased visual acuity (4.3\%). Twenty-nine workers (41.5\%) did not report the use of protective eye wear during work, whereas $22(31.4 \%)$ workers reported occasional use and $19(27.1 \%)$ workers reported routine use (Table 1). The daytime working hours was the same for the workers occasionally or regularly using goggles. Work-related eye injuries occurring despite the workers using eye protection included photokeratitis, superficial foreign bodies in eyes, corneal abrasion, and blunt injury.

Table 2. Variables in terms of duration and age of the workers

\begin{tabular}{|c|c|c|c|c|c|c|}
\hline Parameters & & $\mathbf{n}$ & $\begin{array}{l}\text { Duration of work (years) } \\
\text { Mean } \pm \text { SD (median) }\end{array}$ & $\mathbf{p}$ & $\begin{array}{l}\text { Age (years) } \\
\text { Mean } \pm S D\end{array}$ & $\mathbf{p}$ \\
\hline Corneal scar & No & 41 & $11.8 \pm 11.0(8.0)$ & 0.848 & $33.1 \pm 9.0$ & 0.435 \\
\hline \multirow[t]{2}{*}{ Vision loss } & No & 67 & $11.6 \pm 10.4(8.0)$ & \multirow[t]{2}{*}{-} & $33.3 \pm 8.6(33.0)$ & \multirow[t]{2}{*}{-} \\
\hline & Yes & 3 & $17.7 \pm 20.1(12.0)$ & & $45.0 \pm 10.6(49.0)$ & \\
\hline \multirow{2}{*}{ Goggles use } & Occasional & 22 & $18.5 \pm 11.1(20.0)$ & \multirow{2}{*}{0.001} & $37.8 \pm 8.7(37.5)$ & \multirow{2}{*}{$0.001^{*}$} \\
\hline & Routine & 19 & $11.3 \pm 9.5(10.0)$ & & $35.9 \pm 7.1(37.0)$ & \\
\hline \multirow[t]{2}{*}{ Drug use } & No & 52 & $13.4 \pm 11.6(10.0)$ & \multirow[t]{2}{*}{0.078} & $34.5 \pm 9.2(35.0)$ & \multirow[t]{2}{*}{0.228} \\
\hline & Yes & 18 & $7.2 \pm 5.9(7.0)$ & & $31.6 \pm 8.1(31.5)$ & \\
\hline
\end{tabular}

*Post-hoc analysis revealed patients who do not use googles significanly differ from patients who use them occasionaly and routinely for the duration of their work and age. 


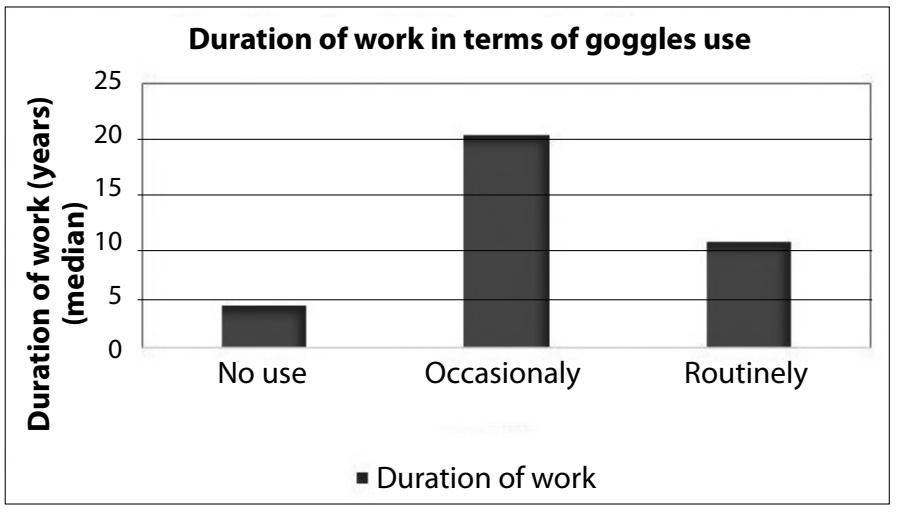

Figure 1. Duration of work in terms of goggles use

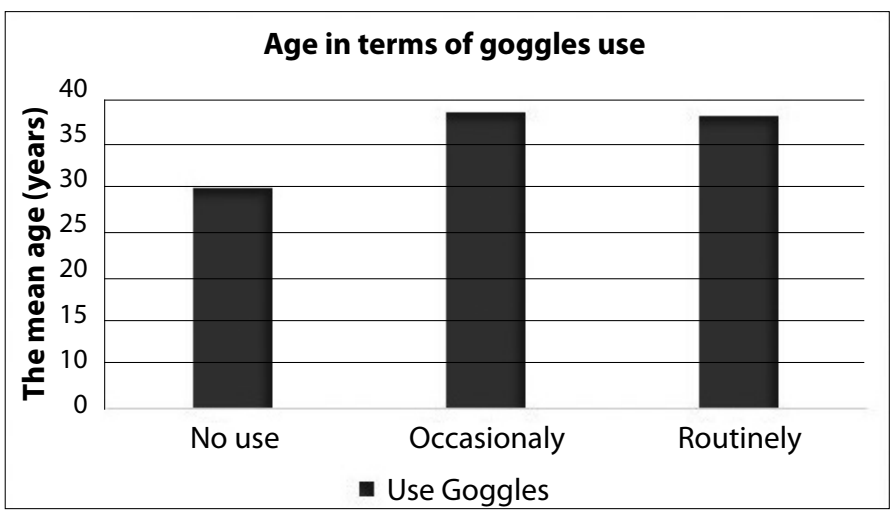

Figure 2. The mean age in terms of goggles use

The unprescribed use of drugs to decrease burning and foreign body sensations in the eyes was investigated. Topical drugs were used to reduce the complaints of injury. It was reported that the drugs were started the same day of the injury and used until the end of the complaints. Eighteen workers (25.7\%) remarked on having topical drug use from time to time. Ten of the 18 patients $(55.6 \%)$ were using topical Tetrahydrozoline hydrochloride $(\mathrm{HCl})$, five $(27.8 \%)$ were using the topical anesthetic drug $0.5 \%$ Proparacaine $\mathrm{HCl}$, one was using (5.5\%) topical Proparacaine $\mathrm{HCl}$ and Diclofenac sodium, and two workers (11.1\%) were using topical Diclofenac sodium (Table 1). Tetrahydrozoline HCL and Diclofenac sodium can still be bought from pharmacys without a prescription, whereas Proparacaine $H C L$ sales were banned by the Turkısh Goverment a few years ago.

There was no significance difference in the duration of work in terms of corneal scar presence $(p=0.848)$ (Table 2). Because there were only three workers with visual problems due to corneal scars, no statistical comparisons were made.

There was a significant difference in the duration of work regarding the use of protective eyewear (median:4; 20; 10; years, respectively, $\mathrm{p}=0.001$ ) (Table 2). Post-hoc analysis revealed the median years of working for patients who were not using protective eyewear was significantly different from the remaing two groups, whereas there were no difference between the two groups (Table 2) (Figure 1).

There were no significant difference in the duration of work in terms of drug use [drug users median: 7 years vs non-drug users: 10 years; $(p=0.078)]$. There was no age difference regarding the presence of corneal scars $(p=0.435)$ Because there were only three workers with visual problems due to corneal scars, no statistical comparisons were made.
There was a significant difference of age regarding the lack of usage of goggles, or occasional or routinel usage [29.3 \pm 8.5 vs. $37.8 \pm 8.7$ vs. $35.9 \pm 7.1$, years, respectively, $(p=0.001)]$. Post-hoc analysis revealed that the ages of patients who did not use googles were significantly younger than for the other groups but there were no difference between the patients with occasional or routine google usage (Table 2) (Figure 2).

There were no significant difference of age in terms of drug use $(p=0.228)$. Because there were only two workers without health insurance, no statistical analysis was conducted.

\section{Discussion}

In our study, we evaluated metal workers with eye injuries due to corneal foreign bodies in their eyes, in terms of eye health and occupational health and safety. We found that 68 (97.1\%) of the metal workers had health insurance, whereas two workers were not insured. The duration of work ranged from 6 months to 40 years, and the mean duration of work was $11.8 \pm 10.8$ years. All of the metal workers with CFBI were male in our study. The mean age of the workers was 33.8 \pm 8.9 years (range 16-53). Similarly, in the study of Ozkurt et al. (5), all the workers with foreign body eye injuries were males and their mean age was $32.5 \pm 1.0$ (range 14-57) years. WREI have been reported to be more common among young male workers $(8,15)$.

According to Turkish Social Security Instutition statistical data, there are 18,350,000 active employees with insurance, which is almost $25 \%$ of the total population. The percentage of the workforce not registered in the social security instutition corresponds to $36.2 \%$ of the total population; $83 \%$ of these unregistered workers are employed in agriculture, and the remaining $27 \%$ are employed in non-agricultural industries (16). Statistical data indicates that there were 74.871 occupational injuries, of which 1.596 (2.1\%) were eye injuries. Work-related injuries are more common among males between 30 and 34 years of age and among workers with a duration of work more than 3 months and less than 1 year (16). A study reported that $15 \%$ of work-related injuries consisted of eye injuries in Australia (17).

It has been reported that, in Turkey, WREl are more common among workers in metal work and machinery industries (2). The most common cause of eye injuries are due to corneal foreign bodies $(5,6,18)$. Corneal metallic foreign body injury, which is preventible, makes up a substantial part of ophtalmological emergencies $(8,9)$. It has been known that work-related eye injuries can be significantly reduced and prevented with the use of protective eye wear $(4,19,20)$. Besides, being experienced, having occupational safety training before work, and the routine maintainance and care of machineries and tools are reported to decrease eye injuries (1).

In our study, we also evaluated the usage of protective eye wear. Twenty-nine (41.4\%) workers were not using glasses during work. Of the 41 workers using goggles, 22 (31.4\%) reported occasional and 19 (27.1\%) workers reported routine use during work. We found that the mean duration (years) of work was significantly lower in workers who did not use glasses than in workers using goggles. Contrary to our expectations, the duration of work was significantly higher in workers with occasional goggle use than in workers routinely using goggles $(18.5 \pm 11.1 ; 11.3 \pm 9.5$ years, respectively). Ozkurt et al. (5) reported that although $64 \%$ of metal workers had been using protective eye wear, among these, patients $57 \%$ were not using goggle during 
eye injury, and $43 \%$ of the injuries occured even though the workers were using protective eye wear (5).

In the present study, the mean number of estimated CFBI in workers was $10.9 \pm 11.2$ (range: $1-50$ ). Corneal scars due to corneal foreign bodies were found in 29 (41.4\%) workers. Three workers with corneal scars had decreased visual acuity because of the scars (4.3\%). Ramakrishnan et al. (9) reported that the rate of corneal scar development because of foreign bodies were $88 \%$. In a study from Turkey, Ozkurt et al. (5) reported a 58\% rate of corneal scar development. In our study, fewer corneal scar injuries were seen among our study participants. This result may be related to the early arrival of these workes to our ophthalmology clinic.

Some of the metal workers may use unprescribed ophtalmological drugs to reduce redness and pain due to foreign body exposure. Topical anesthetic $0.05 \%$ Proparacaine $\mathrm{HCl}$ and topical Diclofenac sodium have been used to relieve pain. Tetrahydrozoline HCL $0.05 \%$ decreases redness via ophtalmic vasoconstriction (21). Topical Diclofenac drop has anti-inflammatory and corneal hypoaesthetic effects (22). The long-term use of topical Diclofenac following ocular surgery has been reported to cause corneal melting (23). On the other hand, the long-term use of topical $0.05 \%$ Proparacaine $\mathrm{HCl}$ drop may lead to several eye problems, including superficial punctate keratopathy, persistent epithelial defects, stromal infiltrates, and secondary infectious keratitis (10-13). Keratoplasty may be necessary in cases with corneal abscess due to the abuse of eye drops (13).

When unprescribed ophtalmological drugs, i.e., without physician recommendation, to decrease burning and foreign body sensations in the eyes during metal cutting and foreign body exposure were investigated, it was found that 18 workers $(25.7 \%)$ had unprescribed drug use. Ten of the 18 patients (55.6\%) were using topical Tetrahydrozoline $\mathrm{HCl}$, five (27.8\%) were using the topical anesthetic drug $0.5 \%$ Proparacaine $\mathrm{HCl}$, one was using (5.5\%) topical Proparacaine $\mathrm{HCl}$ and Diclofenac sodium, and two workers were on $(11.1 \%)$ topical Diclofenac sodium. No complication due to drug use was detected. The age and duration of work were not significantly associated with drug usage. Workers who were using unprescribed drugs were informed about their effects, side effects, and possible complications. Due to the high reported complications and side effects of Proparacaine $\mathrm{HCl}$ (10-13), it has been forbidden to be sold without prescription in Turkey.

In order to prevent work-related injuries, training must be provided to workers to improve work skills and knowledge of occupational hazards and the prevention of accidents before beginning active work (1).

The most simple and effective protection for eye injuries is the use of goggles. Unprescribed drug usage without proper medical indication, which may lead to serious side effects, must be avoided. Workers must be informed on the side effects of these drugs, especially during long-term and improper use. It must be kept in mind that health and safety education is important to prevent eye injuries.

\section{Study limitations}

There were several limitations in our study. First, the sample size was small in our study; second, the kinds of eye injury were not separated; and third, the study did not assess the working conditions. In addition, the information about injuries was learned from in-person interviews. Workers may not always show an objective attitude to protecting the workplace in terms of the use of glasses and drugs.

\section{Conclusion}

Our study concludes that eye injuries may be reduced by better education of the workers about risky behaviors and by persuading them to comply with safety measures. These goggles should be well-fitted, durable, protective eyewear with good visibility, together with strict compliance on their use. Ophthalmologists should inform patients, primary and emergency doctors, and pharmacists about potential permanent visual loss associated with topical anesthetic abuse and other unprescribed drug usage, such as Tetrahydrozoline $\mathrm{HCl}$ and Diclofenac sodium.

Ethics Committee Approval: Ethics committee approval was received for this study from the ethics committee of Fatih University Clinical Research Ethics Commission.

Informed Consent: Written informed consent was obtained from patients who participated in this study.

Peer-review: Externally peer-reviewed.

Conflict of Interest: No conflict of interest was declared by the authors.

Financial Disclosure: The authors declared that this study has received no financial support.

\section{References}

1. Yu TS, Liu H, Hui K. A case-control study of eye injuries in the workplace in Hong Kong. Ophthalmology 2004; 111: 70-4. [CrossRef]

2. Serinken M, Turkcuer I, Cetin EN, Yilmaz A, Elicabuk H, Karcioglu O. Causes and characteristics of work-related eye injuries in western Turkey. Indian J Ophthalmol 2013; 61: 497-01. [CrossRef]

3. Kanoff JM, Turalba AV, Andreoli MT, Andreoli CM. Characteristics and outcomes of work-related open globe injuries. Am J Ophthalmol 2010; 150: 265-9. [CrossRef]

4. Bull N. Mandatory use of eye protection prevents eye injuries in the metal industry. Occup Med (Lond) 2007; 57: 605-6. [CrossRef]

5. Ozkurt ZG, Yuksel H, Saka G, Guclu H, Evsen S, Balsak S. Metallic corneal foreign bodies: an occupational health hazard. Arq Bras Oftalmol 2014 77: 81-3. [CrossRef]

6. Gumus K, Karakucuk S, Mirza E. Corneal injury from a metallic foreign body: an occupational hazard. Eye Contact Lens 2007; 33: 259-60. [CrossRef]

7. Zghal-Mokni I, Nacef L, Kaoueche M, Letaief I, Bouguila H, Jeddi A, et al. Epidemiology of work-related eye injuries. Tunis Med 2007; 85: 576-9.

8. Yigit $\mathrm{O}$, Yuruktumen A, Arslan S. Foreign body traumas of the eye managed in an emergency department of a single-institution. Ulus Travma Acil Cerrahi Derg 2012; 18: 75-9. [CrossRef]

9. Ramakrishnan T, Constantinou M, Jhanji V, Vajpayee RB. Corneal metallic foreign body injuries due to suboptimal ocular protection. Arch Environ Occup Health 2012; 67: 48-50. [CrossRef]

10. Yeniad B, Canturk S, Esin Ozdemir F, Alparslan N, Akarcay K. Toxic keratopathy due to abuse of topical anesthetic drugs. Cutan Ocul Toxicol 2010; 29: 105-9. [CrossRef]

11. Erdem E, Undar IH, Esen E, Yar K, Yagmur M, Ersoz R. Topical anesthetic eye drops abuse: are we aware of the danger? Cutan Ocul Toxicol 2013; 32: 189-93.

12. Aksoy A, Başkan AM, Aslan L, Aslankurt M. Topical proparacaine abuse resulting in evisceration. BMJ Case Rep 2013; 2013. pii: bcr2013009539.

13. Yagci A, Bozkurt B, Egrilmez S, Palamar M, Ozturk BT, Pekel H. Topical anesthetic abuse keratopathy: a commonly overlooked health care problem. Cornea 2011; 30: 571-5. [CrossRef] 
14. McCall BP, Horwitz IB, Taylor OA. Occupational eye injury and risk reduction: Kentucky workers' compensation claim analysis 1994-2003. Inj Prev 2009; 15: 176-82. [CrossRef]

15. Lipscomb HJ. Effectiveness of interventions to prevent work-related eye injuries. Am J Prev Med 2000; 18: 27-32. [CrossRef]

16. Social Insurance Institution Yearly Statistical Report, 2012. Turkey Social Security Institution Web Site. Available from: http://www.ssk.gov.tr. (Accessed 20 September 2010).

17. Fong $L P$, Taouk $Y$. The role of eye protection in work-related eye injuries. Aust N Z J Ophthalmol 1995; 23: 101-6. [CrossRef]

18. Aziz MA, Rahman MA. Corneal foreign body--an occupational hazard. Mymensingh Med J 2004; 13: 174-6.

19. Chen SY, Fong PC, Lin SF, Chang CH, Chan CC. A case-crossover study on transient risk factors of work-related eye injuries. Occup Environ Med 2009; 66: 517-22. [CrossRef]
20. Mancini G, Baldasseroni A, Laffi G, Curti S, Mattioli S, Violante FS. Prevention of work related eye injuries: long term assessment of the effectiveness of a multicomponent intervention among metal workers. Occup Environ Med 2005; 62: 830-5. [CrossRef]

21. Abelson MB, Butrus $\mathrm{SI}$, Weston $\mathrm{JH}$, Rosner B. Tolerance and absence of rebound vasodilation following topical ocular decongestant usage. Ophthalmology 1984; 91: 1364-7. [CrossRef]

22. Aragona P, Tripodi G, Spinella R, Laganà E, Ferreri G. The effects of the topical administration of non-steroidal anti-inflammatory drugs on corneal epithelium and corneal sensitivity in normal subjects. Eye (Lond) 2000; 14: 206-10. [CrossRef]

23. Lin JC, Rapuano CJ, Laibson PR, Eagle RC Jr, Cohen EJ. Corneal melting associated with use of topical nonsteroidal anti-inflammatory drugs after ocular surgery. Arch Ophthalmol 2000; 118: 1129-32. 